\title{
Etiology of thumb sucking habit and its effect on developing malocclusion
}

\author{
Zahid Nisar Ahmed ${ }^{1 *}$, Ahmed Mahmoud Hussin², Anoud Fahad Alanazi ${ }^{3}$, \\ Abdullah Mohammed Alhuraish ${ }^{4}$, Sarah Abdullah Abomelha ${ }^{5}$, Thabt Hassan Tulbah ${ }^{6}$, \\ Aidel Abdullah Alshahrani ${ }^{5}$, Alanoud Fahad Alotaibi ${ }^{7}$, Walaa Amer Alkheshail ${ }^{8}$, \\ Waleed Khalid Almalki ${ }^{9}$, Waed Shaker Alshaikh ${ }^{10}$, Ali Mohammed Aldossari ${ }^{8}$
}

\author{
${ }^{1}$ Department of Orthodontics, ${ }^{2}$ Departement of Cosmetic Dentistry, Alwadq Almasi Medical Complex, Al Mouhaideb \\ Dental Clinic, Taif, Saudi Arabia \\ ${ }^{3}$ College of Dentistry, Ajman University of Science and Technology, Ajman, UAE \\ ${ }^{4}$ College of Dentistry, University of Hail, Hail, Saudi Arabia \\ ${ }^{5}$ General Dentist, Ministry of Interior, Riyadh, Saudi Arabia \\ ${ }^{6}$ General Dentist, Alnoor Specialist Hospital, Mecca, Saudi Arabia \\ ${ }^{7}$ College of Dentistry, Riyadh Elm University, Riyadh, Saudi Arabia \\ ${ }^{8}$ General Dentist, Ministry of Health, Riyadh, Saudi Arabia \\ ${ }^{9}$ College of Dentistry, King Saud University, Riyadh, Saudi Arabia \\ ${ }^{10}$ Department of Maxillofacial Surgery, Dammam Medical Complex, Dammam, Saudi Arabia
}

Received: 15 December 2020

Accepted: 31 December 2020

\section{*Correspondence:}

Dr. Zahid Nisar Ahmed,

E-mail: Zad1912@hotmail.com

Copyright: ( ) the author(s), publisher and licensee Medip Academy. This is an open-access article distributed under the terms of the Creative Commons Attribution Non-Commercial License, which permits unrestricted non-commercial use, distribution, and reproduction in any medium, provided the original work is properly cited.

\begin{abstract}
The persistence of thumb sucking might also be harmful as it might be associated with the development of complications seen on the thumb as paronychia and nail deformities and in the mouth level as malocclusions. In this review, we have looked up studies in the literature to identify the effect of thumb sucking on the development of malocclusion. Thumb sucking in children usually occurs as a primitive reflex that appears in early childhood with no apparent causative factors. Children usually develop this thumb sucking habit because in this way they feel more comfortable and secure. The main cause behind the development of thumb sucking is the prolonged presence of the thumb in the mouth which creates pressure against the developing jaw and teeth. This may interfere with the process of tooth eruption leading to delayed or abrupt eruption events and malformations. The severity of malocclusion deformities is significantly associated with the chronicity and period of thumb-sucking habits. Other forms of occlusions secondary to thumb sucking include: anterior open bite, exaggerated overjet, posterior crossbite, retrognathic mandible, a diastema, temporomandibular joint disorders and the retroclined low anterior. Thumb sucking, however, is a self-limiting phenomenon and usually disappears as children grow older. However, when persistence is noticed, immediate management should be approached to avoid any potential complications.
\end{abstract}

Keywords: Thumb sucking, Breastfeeding, Oral development, Malocclusion

\section{INTRODUCTION}

Thumb and digit sucking is the earliest sign of muscular coordinated activity that the child develops in his early months and is considered a physiological process. Breastfeeding is considered as a natural nutritive sucking effect and it helps in the development of the muscular oral activities as it requires the coordination of many 
efforts regarding the integrity of the oral muscular system. ${ }^{1,2}$ Such integration which frequently occurs helps in the process of molar development of the child as it increases the muscle tone, and therefore, contributing to developing sound oral functions. ${ }^{3}$ On the other hand, using other oral habits as bottle feeding and pacifiers might interfere with the development of abnormal developmental functions and might be associated with some complications. ${ }^{4}$ Pires et al showed that lower masticatory functions were associated with a 6 month use of pacifiers and a 12 month use of bottle feeding in children. $^{4}$

Non-nutritive sucking habits may develop as a result of insufficient breastfeeding by the mother which pushes the baby to develop other similar techniques. ${ }^{5}$ The aim of developing such habits is to compensate for any frustration they might face, due to reduced feeling of insecurity or may be due to the need to contact which can be done with breastfeeding. ${ }^{6}$ Many studies have previously investigated the correlation between breastfeeding and non-nutritive habits and their effect on the oral structural development of the child..$^{7,8}$

Non-nutritive sucking habits are a group of disorders that have been found to simultaneously occur in children or following the presence of external stimuli as the absence of breastfeeding. Among these habits, thumb sucking is a common event that is usually found in young infants. ${ }^{9}$ Other events in the non-nutritive sucking habits group include the use of pacifiers, blankets, or other digits sucking that is usually done as an approach of comfort by the child. Kumar et al mentioned that children that develop sucking habits usually do it as an adaptive approach as it provides self-soothing and/or stimulation. ${ }^{10}$ Sucking habits are common in young infants, however, as children grow older, sucking habits tend to decrease and disappear. Research shows that it fades away by the age of 4-6 years old. ${ }^{11}$

On the other hand, the persistence of thumb sucking might also be harmful as it might be associated with the development of complications on the thumb level as paronychia and nail deformities and in the mouth as malocclusions. ${ }^{11}$ Malocclusion occurs when this habit persists during eruption and dentition. Many management approaches can be done. These include approaching the parents of the affected child with relevant advice behavior modification, counselling, and the application of a calendar with rewards for the child. ${ }^{9}$ Therefore, such habits should be given enough care and early referral systems should be applied for the sound management of this approach. ${ }^{10,11}$ In this review, we have looked up studies in the literature to identify the etiology and possible effect of thumb sucking on the development of malocclusion.

An extensive literature search of the Medline, Cochrane, and EMBASE databases was performed on 18 December 2020 using the medical subject headings (MeSH) or a combination of all possible related terms. Studies discussing the etiology and possible effect of thumb sucking on the development of malocclusion were screened for relevant information. We did not pose any limits on date, language, or publication type.

\section{ETIOLOGY AND EPIDEMIOLOGY OF THUMB SUCKING}

Thumb sucking in children usually occurs as a primitive reflex that appears in early childhood with no apparent causative factors. Children usually develop thumb sucking habit because in this way they feel more comfortable and secure. Pacifiers have also been introduced by caregivers personnel to make the infant calmer when agitation occurs. Ferrante et al conducted a study in Italy and showed that thumb sucking in their population of children was done to relieve the potential presence of any physical and psychological stress by creating a state of muscular balance through stimulation of the nasopalatal receptors. ${ }^{12}$ Consequently, the development of thumb sucking appears to be associated with the physical-emotional state of the children. Kumar et al reported that most of the thumb sucking events that occur in early childhood usually fade away spontaneously at the age of four following the development of other management procedures for any psycho emotional distress that the child might face. ${ }^{10}$

Thumb and finger sucking, which are two of the nonnutritive sucking habits that children might develop in their early life, are proven to occur in a high proportion of children globally with no discrimination regarding the socioeconomic status of the child. ${ }^{11}$ However, it has been found that the incidence of these phenomena is variable among different geographical places. In Sweden, the incidence rate of all the non-nutritive sucking habits has been estimated to be $82 \%$ within the first five months since birth. In the United States, a lower incidence rate of $73 \%$ has been reported; however, the age range was different from that of the Sweden rate, being 2-5 years of age. Studies also showed that such habits tend to disappear when children grow up. Moreover, it has been estimated that at four years of age, around $48 \%$ of children develop non-nutritive sucking habits. This rate begins to decrease as children grow older to reach a rate of $12.1 \%$ when the child reaches the age of seven. Thumb sucking habit might also persist in many children at the age of 12 years old with an estimated rate of $1.9 \% .^{9}$

\section{EFFECT OF THUMB SUCKING ON DEVELOPING OCCLUSIONS}

The chronic persistence of a non-nutritive sucking habit like thumb sucking can lead to serious complications in facial structures, especially the anterior open bite. The habit of finger or thumb sucking may be associated with the development of asymmetrical anterior open bite. This deformity usually happens and is marked worst in relation to the anatomical position where the non-nutritive 
sucking habit occurs. It is worth mentioning that complications are hugely dependant on the chronicity and frequency of the habit. ${ }^{13}$ The main cause behind the development of thumb sucking is the prolonged presence of the thumb in the mouth which creates pressure against the developing jaw and teeth. This may interfere with the process of tooth eruption leading to delayed or abrupt eruption events and malformations. Freire et al conducted a study on children that had the habit of finger sucking and found that in these children, the risk for developing malocclusions from finger sucking increased by 4.25 than other children that did not have a history of finger sucking. ${ }^{14}$ Borrie et al also proved that the severity of malocclusion deformities is significantly associated with the chronicity and period of the thumb-sucking habits. ${ }^{9}$ The authors also showed that, in addition to the malocclusions, the thumb which the child uses in this habit, may also be affected and present with some complications and deformities, the management of which may require surgical intervention in some cases. The presence of these complications might affect the sound development of the oral structures and the related functions in the child. Other complications such as speech and behavioral disorders may also be present; however, the evidence of association is poor. Baker et al conducted a study on an Australian population that consisted of preschool children to investigate the association between the presence of thumb sucking habits and whether it has an impact on the investigated children's phonological functions. ${ }^{15}$ The authors reported that they could not find any association between the presence of thumb sucking habits and whether it affected the phonological characteristics of the affected children. On the other hand, Barbosa et al conducted a similar study on 128 children that had speech disorders and found that among these children, $18.3 \%$ had a history of non-nutritive sucking habits especially thumb-sucking. ${ }^{16}$

Other forms of occlusions secondary to thumb sucking habit include, in addition to anterior open bite, exaggerated overjet, posterior crossbite, diastema, temporomandibular joint disorders, and the presence of the mandible in a retracted position. In a meta-analysis of 15 studies conducted by Sikorska et al the authors reported that the persistence of oral habits such as thumb and finger sucking was associated with the development of mastication anomalies, in addition to the development of occlusion in children that present with such habits. ${ }^{17}$ Louis et al reported a positive correlation between the development of occlusions secondary to thumb sucking and the socio-economic status of the affected child. ${ }^{18}$ Another study by Moss et al proved that many complications such as dental malocclusions are associated with the prolonged presence of oral habits like thumb sucking in their Greek population of children. ${ }^{19}$

Another study by Lopez et al on a preschool population of children in Peurto Rico to find the association between the presence of oral habits such as thumb sucking and the development of relevant complications like malocclusion and whether such events can be prevented by breastfeeding habits. ${ }^{20}$ The authors reported that $32 \%$ of their population had the habit of thumb sucking and malocclusion abnormalities including space deficiency, open bites, and crossbites, which were noticed among $90 \%$ of their patients. However, thumb-sucking was not the only reported oral habit among these children, but a history of bottle feeding was also reported. The authors also reported that there was a significant correlation between the initiation of breastfeeding and the prevention of malocclusion complications secondary to the aforementioned oral habits. A serial study by Sillman et al studied the effect of thumb sucking on tooth eruption and the subsequent presence of secondary complications. $^{21}$ The authors reported that although a thumb-sucking behavior can cause teeth displacement, it does not interfere with the development of molar eruption and relationships. The findings from the same study also showed that thumb-sucking was associated with the presence of side effects in patients with poor bites; however, such effects were negligible in patients with good bites. In a large study of 1114 children between two to five years of age in Hong Kong, the authors investigated the correlation between non-nutritive sucking habits and the development of malocclusion in their population. The authors reported that thumb sucking was significantly associated with the development of overjet and anterior open bite in addition to the significant association between the same habit and the development of class II and III incisor and canine relationships, respectively. The authors also reported that the daily use of pacifiers for more than one year was significantly associated with the development of thumb-sucking habits. ${ }^{22}$ Warren et al conducted a longitudinal study on 372 children to study the effect of nutritive and nonnutritive sucking habits and their effect on dental arches and primary dentition. The authors reported that the persistence of thumb-sucking and digital habits for over 48 months was significantly associated with malocclusion parameters as anterior open arch and overjet. ${ }^{23}$ In a Japanese study of 42-month old children, the authors reported that malocclusion deformities as maxillary protrusion and open bites were significantly associated with $70.7 \%$ of these children. The authors also reported that in patients that discontinued the thumb-sucking habits, this rate was hugely decreased to $6.8 \%$ only. ${ }^{24}$ The international Avon longitudinal study conducted by Duncan and colleagues investigated the prevalence of oral sucking habits at different ages of the included children. The authors reported that a rate of $63.2 \%$ of the included patients developed sucking habits by the age of 15 months; however, this rate was markedly reduced to $40 \%$ by the age of 36 months old. The authors reported that the presence of these habits was associated with the development of dentition deformities as open bites and posterior crossbites. ${ }^{25}$

\section{CONCLUSION}

In this study, we have reviewed the etiology and epidemiology of thumb sucking and its effect on the development of malocclusion in children. Although this 
phenomenon might be a benign condition, appropriate management should be approached when persistence beyond the expected age was noticed. Many forms of occlusions secondary to thumb sucking include anterior open bite exaggerated overjet, posterior crossbite, a diastema, temporomandibular joint disorders, and the presence of the mandible in a retracted position. Therefore, the management of such a phenomenon is urgent to avoid such complications, and frequent followup and urgent referral should be applied for proper management and prevention.

\section{Funding: No funding sources}

Conflict of interest: None declared

Ethical approval: Not required

\section{REFERENCES}

1. Narbutytė I, Narbutytė A, Linkevičienè L. Relationship between breastfeeding, bottle-feeding and development of malocclusion. Stomatologija. 2013;15(3):67-72.

2. Rochelle IMF, Tagliaferro EPDS, Pereira AC, Meneghim MDC, Nóbilo KA, Ambrosano GMB. Breastfeeding, deleterious oral habits and malocclusion in 5-year-old children in São Pedro, SP, Brazil. Dental Press J Orthod. 2010;15(2).

3. Chen X, Xia B, Ge L. Effects of breast-feeding duration, bottle-feeding duration and non-nutritive sucking habits on the occlusal characteristics of primary dentition. BMC Pediatr. 2015;15:46.

4. Pires SC, Giugliani ER, Caramez da Silva F. Influence of the duration of breastfeeding on quality of muscle function during mastication in preschoolers: a cohort study. BMC Public Health. 2012;12(1):934.

5. Turgeon-O'Brien $\mathrm{H}$, Lachapelle $\mathrm{D}$, Gagnon PF, Larocque I, Maheu-Robert LF. Nutritive and nonnutritive sucking habits: a review. J Dent Child. 1996;63(5):321-7.

6. Jyoti S, Pavanalakshmi G. Nutritive and nonnutritive sucking habits-effect on the developing orofacial complex; a review. Dentistry. 2014;4(3):1-4.

7. Moimaz SA, Zina LG, Saliba NA, Saliba O. Association between breast-feeding practices and sucking habits: a cross-sectional study of children in their first year of life. J Indian Soc Pedod Prev Dent. 2008;26(3):102-6.

8. Agarwal SS, Nehra K, Sharma M, Jayan B, Poonia A, Bhattal H. Association between breastfeeding duration, non-nutritive sucking habits and dental arch dimensions in deciduous dentition: a cross-sectional study. Prog Orthod. 2014;15(1):59.

9. Borrie FR, Bearn DR, Innes NP, Iheozor-Ejiofor Z. Interventions for the cessation of non-nutritive sucking habits in children. Cochrane Database Syst Rev. 2015(3):Cd008694.

10. Kumar V, Shivanna V, Kopuri RC. Knowledge and attitude of pediatricians toward digit sucking habit in children. J Indian Soc Pedod Prev Dent. 2019;37(1): 18-24.

11. Nasir A, Nasir L. Counseling on early childhood concerns: sleep issues, thumb-sucking, picky eating, school readiness, and oral health. Am Fam Physician. 2015;92(4):274-8.

12. Ferrante A, Ferrante A. Finger or thumb sucking, new interpretations and therapeutic implications. Minerva Pediatr. 2015;67(4):285-97.

13. Tanny L, Huang B, Naung NY, Currie G. Nonorthodontic intervention and non-nutritive sucking behaviours: A literature review. Kaohsiung J Med Sci. 2018;34(4):215-22.

14. Lopes Freire GM, Espasa Suarez de Deza JE, Rodrigues da Silva IC, Butini Oliveira L, Ustrell Torrent JM, Boj Quesada JR. Non-nutritive sucking habits and their effects on the occlusion in the deciduous dentition in children. Eur J Paediat Dent. 2016;17(4):301-6.

15. Baker E, Masso S, McLeod S, Wren Y. Pacifiers, Thumb Sucking, Breastfeeding, and Bottle Use: Oral Sucking Habits of Children with and without Phonological Impairment. Folia Phoniatr Logop. 2018;70(3-4):165-73.

16. Barbosa C, Vasquez S, Parada MA. The relationship of bottle feeding and other sucking behaviors with speech disorder in Patagonian preschoolers. BMC Pediatr. 2009;9:66.

17. Sikorska A, CudzjBo D, Matthew-Kozanecka M, Turska-MaljDska R. Impact of incorrect oral habits on mastication anomalies in children and adolescents - literature review and own observations. Dev Period Med. 2016;204:325-7.

18. Calisti LJ, Cohen MM, Fales MH. Correlation between malocclusion, oral habits, and socioeconomic level of preschool children. J Dent Res. 1960;39:450-4.

19. Moss JP, Picton DC. The problems of dental development among the children on a Greek island. Dent Pract Dent Rec. 1968;18(12):442-8.

20. López Del Valle LM, Singh GD, Feliciano N, Machuca Mdel C. Associations between a history of breast feeding, malocclusion and parafunctional habits in Puerto Rican children. P R Health Sci J. 2006;25(1):31-4.

21. Sillman JH. Thumb-sucking and the oral structures a serial study from birth to 14 years of age. J Pediatr. 1951;39(4):424-30.

22. Ling HTB, Sum FHKMH, Zhang L. The association between nutritive, non-nutritive sucking habits and primary dental occlusion. BMC Oral Health. 2018;18 (1):145-5.

23. Warren JJ, Bishara SE. Duration of nutritive and nonnutritive sucking behaviors and their effects on the dental arches in the primary dentition. Am J Orthod Dentofacial Orthop. 2002;121(4):347-56.

24. Ozawa N, Hamada S, Takekoshi F, Shinji H. A study on non-nutritive sucking habits in young Japanese children, relationships among incidence, duration, 
malocclusion and nursing behavior. Pediatr Dent J. 2005;15(1):64-71.

25. Duncan K, McNamara C, Ireland AJ, Sandy JR. Sucking habits in childhood and the effects on the primary dentition: findings of the Avon longitudinal study of pregnancy and childhood. Int $\mathbf{J}$ Paediatr Dent. 2008;18(3):178-88.

Cite this article as: Ahmed ZN, Hussin AM, Alanazi AF, Alhuraish AM, Abomelha SA, Tulbah TH, et al. Etiology of thumb sucking habit and its effect on developing malocclusion. Int J Community Med Public Health 2021;8:905-9. 